\title{
A STUDY ON THE READING SKILLS OF EFL UNIVERSITY STUDENTS
}

\author{
Flora Debora Floris \\ Marsha Divina \\ Petra Christian University, Indonesia
}

\begin{abstract}
The present study attempts to investigate kinds of reading skills that EFL (English as a Foreign Language) University students have difficulty with. For this purpose, two reading tests which covered seventeen kinds of reading skills were developed and administered to ten students of batch 2003 studying at an English Department of a private university in Surabaya, Indonesia. The analysis showed that each reading skill had different level of difficulty for the respondents.
\end{abstract}

Key words: teaching reading, testing reading, reading skills

Studies have shown that EFL students who read a lot seem to acquire English better than those who do not. They "do not only improve in their reading abilities, but also improve in using and increasing their English abilities and knowledge. Without getting much exposure to reading materials in class, EFL students are unlikely to make much progress (Nation, 1997, p. 7). Realizing the importance of reading for EFL students, it is then very crucial for EFL students to have good reading proficiency. Having good reading proficiency means the reader has abilities to understand written statements or any type of written texts accurately and efficiently (Mahfoodh, 2007, p.1).

Reading proficiency is determined by reading skills. According to Wassman and Rinsky (2000, p. 2, cited in Suparman, 2005, p. 141),

To understand all the printed materials in English, high reading proficiency is of paramount importance without which the information will not be comprehended. However, it takes an "effective reader" to make sense out of the print with which EFL students are bombarded daily. Thus, becoming an effective reader means the reader has reading skills and knows how to use them effectively. 
Nuttall (1996, pp.44-124) suggests that there are three major categories of reading skills namely efficient reading skills, word attack skills, and text attack skills. Each category is divided into sub-skills as follows:

1 Efficient reading skills are divided into five sub-skills, i.e. identifying the reason for reading, choosing the right material, using the text effectively, making use of all the resources in the text, and improving reading speed (pp. 44-61).

2. Word attack skills consist of three sub-skills: the interpretation of structural clues (both syntactical and morphological); inference from context; and the use of the dictionary (pp. 62-76),

3. Text attack skills are comprised of eight sub-skills, i.e.: understanding syntax, recognizing and interpreting cohesive devices, interpreting discourse markers, recognizing functional value, recognizing text organization, recognizing the presuppositions underlying the text, recognizing implications and making inferences, and prediction (pp. 78-124).

McWhorter (2002, pp.386-387, 397-398, 418-419) adds other important reading skills namely distinguishing between fact and opinion, paraphrasing and summarizing.

Considering the importance of mastering reading skills, the writers were interested in doing further investigation about the reading skills of EFL students. The study was guided by the following research questions:

1. What are the types of reading skills that EFL students have difficulty with?

2. What is the most difficult type of reading skills for these EFL students?

\section{METHOD}

Due to the limited time available, for this present study, the writer focused on the investigation of the reading skills of ten batch-2003-students studying at an English Department of a private university in Surabaya. Batch-2003students were selected because they had passed all levels of reading classes (4 levels) which meant that they had learnt all essential reading skills.

In doing the data collection, the writers used some steps. The first step was to analyze the kinds of reading skills which were taught in Reading One, Reading Two, Reading Three, and Reading Four classes at the department. It was found that in these classes, the students did not learn all the reading skills pro- 
posed by Nuttall (1996) and McWhorter (2002). Considering this situation, the writers decided to focus on seventeen reading skills which were already taught namely:

scanning

skimming

improving reading speed

structural clues: morphology (word part)

structural clues: morphology (compound words)

inference from context

using a dictionary

interpreting pro-forms

interpreting elliptical expression

interpreting lexical cohesion

recognizing text organization

recognizing presupposition underlying the text

recognizing implications and making inference

prediction

distinguishing between fact and opinion

paraphrasing

summarizing

The second step of the data collection was to develop two reading tests. In developing the tests, the writers used the following steps. First, they adopted two reading texts entitled Learning to be Funny is No Joke and The Birth of Rock by Maker and Lenier (1986) for reading test one and other two reading texts entitled Using the Creative Imagination and Power of the Press by Talok (1992) for reading test two.

After that, they developed test items based on those reading texts. The test items covered seventeen kinds of reading skills mentioned above. The first reading text in each test was followed by test items which covered twelve kinds of reading skills: scanning, skimming, improving reading speed, structural clues: morphology (word part), structural clues: morphology (compound words), inference from context, using a dictionary, interpreting pro-forms, interpreting lexical cohesion, recognizing presupposition underlying the text, recognizing implications and making inference and summarizing. The second reading text in each reading test was followed by test items which covered seven kinds of reading skills: interpreting elliptical expression, recognizing pre- 
supposition underlying the text, prediction, distinguishing between fact and opinion, paraphrasing and summarizing.

Each reading test consisted of thirty four items as the representatives of seventeen kinds of reading skills. There were two items for each reading skills to make sure that respondents' reading skills could be tested and measured well. Short answer type was used instead of multiple choice answer type in order to avoid respondents' guessing in doing the tests (Hughes, 1989, p. 60). Short answers types were hoped to give more accurate picture about the respondents' abilities. An example of the reading test can be found in the appendix.

The writers developed two reading tests because more than one reading test could give more information about the students' or respondents' abilities. This was in line with Weir's (1993, p.20) statement that "Reliability is often connected with taking enough samples of student's work. The more evidence we have of a student's ability the more confident can be in the judgments we make concerning this ability".

The third step was piloting the two reading tests. Three students of batch 2003 who had already passed all reading classes were chosen randomly to try doing the two reading tests in two different times. The piloting of both reading test one and reading test two was administered in similar ways with the administration of the real tests. The piloting was aimed to help the writers to see whether the two reading tests had clear and good instructions and items. In addition, the writers checked whether the time allocation (100 minutes for each test) was sufficient or not. After piloting the two reading tests, the writers did some minor revisions concerning typographical errors and unclear instructions.

The next step of the data collection was to distribute the reading tests to ten students of English Department Batch 2003 students who had already passed all reading classes. These students who were chosen randomly had to do the two reading tests in two different times: May 1, 2007 and May 3, 2007. This was done to improve the reliability of the tests.

The final step of the data collection was to check and count the results of both reading tests. In doing this, the writers used answer keys. If the respondents' answers were correct or in accordance with the answer keys more than $75 \%$, the respondents got full mark. On the other hand, if the respondents' answers were just in accordance with the answer keys less than 75\%, the respondents got zero. 
The first step of data analysis was to analyze the results of each reading test. The results were put in two separated tables. Each table was divided into four columns (refer to the table below). In the first column, the writers wrote seventeen kinds of reading skills which were tested in the reading test. In the second column, the questions' numbers in the reading test which represented a particular kind of reading skill were written. In the third column, the writers put the students' codes who participated in the reading test as respondents. Then they gave a tick $(\sqrt{ })$ for correct answers and cross $(X)$ for wrong answers. Finally, the writers wrote the total number of both correct answers and wrong answers for each reading skill in the fourth column.

\begin{tabular}{|c|c|c|c|c|c|c|c|}
\hline \multirow[t]{2}{*}{$\begin{array}{l}\text { Reading } \\
\text { Skills }\end{array}$} & \multirow[t]{2}{*}{$\begin{array}{l}\text { Questions' } \\
\text { Numbers }\end{array}$} & \multicolumn{4}{|c|}{ Respondents' Code } & \multicolumn{2}{|c|}{$\begin{array}{c}\text { Total } \\
\text { Answers }\end{array}$} \\
\hline & & 1 & 2 & 3 & 4 & Correc & $\begin{array}{l}\text { Incor- } \\
\text { rect }\end{array}$ \\
\hline$\ldots \ldots \ldots \ldots$ & .......... & & & & & & \\
\hline & .......... & & & & & & \\
\hline
\end{tabular}

The next step of data analysis was to list seventeen kinds of reading skills which were tested in the reading tests. Then the percentage of incorrect answer for each reading skill was calculated. The higher the percentage meant the more difficult that particular reading skill for the respondents. If the percentage was low, it was assumed that the skill was easier for the respondents.

\section{FINDINGS}

\begin{tabular}{clc}
\hline No. & \multicolumn{1}{c}{ Kinds of Reading Skills } & $\begin{array}{c}\text { The Difficulty Level (Per- } \\
\text { centage) }\end{array}$ \\
\hline 1. & Recognizing Text Organization & $72.5 \%$ \\
2. & Paraphrasing & $65 \%$ \\
3. & Inference from Context & $57.5 \%$ \\
4. & Summarizing & $47.5 \%$ \\
5. & Skimming & $42.5 \%$ \\
\hline 6. & Structural Clues: Morphology (Compound & $40 \%$ \\
7. & Words) & $40 \%$ \\
8. & Prediction & $37.5 \%$ \\
9. & Interpreting Pro-forms & $37.5 \%$
\end{tabular}




$\begin{array}{llc}\text { 10. } & \text { Structural Clues : Morphology (word parts) } & 35 \% \\ \text { 11. } & \text { Using a Dictionary } & 30 \% \\ \text { 12. } & \text { Interpreting Lexical Cohesion } & 27.5 \% \\ \text { 13. } & \begin{array}{l}\text { Recognizing Implications and Making In- } \\ \text { ferences }\end{array} & 22.5 \% \\ \text { 14. } & \text { Distinguishing between Fact and Opinion } & 17.5 \% \\ \text { 15. } & \text { Improving Reading Speed } \\ \text { 16. } & \text { Recognizing Presupposition Underlying the } & 10 \% \\ & \text { Text } & 10 \% \\ 17 . & \text { Scanning } & 7.5 \%\end{array}$

In this study, recognizing text organization skill which means perceiving the pattern of how ideas hang together in a reading text (Grabe and Stoller, 2002, p.80) was represented by test items number 32 and 33. Respondents were asked to fill in the missing parts of an outline which is based on a particular reading text. The results of data analysis showed that from total 4 items (2 items in each reading test one and reading test two) which were given to ten respondents, $72.5 \%$ of total respondents' answers (or 29 answers) were incorrect. Therefore, it could be assumed that this reading skill was the most difficult reading skill for the respondents.

In this study, paraphrase skill was represented by items number 30 and 31. The respondents had to paraphrase or restate the sentences' original ideas into their own words (McWhorter, 2002, p. 386). In paraphrasing, the respondents can either use synonyms to substitute the original words or rearrange the order of the information of a sentence (pp. 386-387). It was found out that 65\% of respondents' answers were wrong.

Dealing with inference from context skill which means learning words by hearing or seeing the words in the context (Maker and Lenier, 1986, p. 1), the respondents were asked to define the meanings of particular word appeared in a particular reading text. In reading test one, this skill was represented by items number 4 and number 7 . In reading test two, inference from context skill' items were items number 8 and number 9 . The results showed that there were 28 wrong answers toward inference from context's test items in reading test one and reading test two. It meant from the total answers (40 answers), $70 \%$ of the answers were wrong.

Summarizing skill which means restatement of the important points of a passage (McWhorter, 2002, p.397) was represented by items number 23 and 
34. The respondents were asked to make the summary of all the reading texts included in both reading tests. The results of data analysis showed that $47.5 \%$ of respondents' total answers were incorrect.

Skimming is glancing rapidly through a text to determine its gist or main idea (Nuttall, 1996, p.50). Thus, in order to test the respondents' abilities in skimming skill, the respondents were asked to write the main idea of a particular lines or a certain paragraph of a particular reading text. In reading test one, this skill was represented by items number 1 and 2 . In reading test two, skimming skill was represented by items number 1 and 6 . It was found out that 42.5 $\%$ of respondents' total answers was incorrect.

Nuttall (1996, pp. 71-72) says that compound words are those formed by combining two normally independent words, such as software, spoon-fed. The meanings of compound words can often be worked out from the meanings of the component parts. In this study, the respondents were asked to define the meanings of compound words occurred in the reading texts. In reading test one, items number 6 and number 10 represented structural clues: morphology (compound words) skill. In reading test two, items number 4 and number 12 represented this skill. It was found out that $40 \%$ or 16 answers were wrong answers.

In this study, predicting skill which means responding the text by having expectations and ideas about the purpose of the text, as well as ideas about possible outcomes (McDonough and Shaw, 2003 as cited in Bryndal, 2007, p. 2 ) was represented by items number 24 and 25 . The respondents were asked to predict the content of the second reading texts in both reading test one and reading test two. The results of data analysis showed that $40 \%$ or 16 answers were wrong.

The respondents were also asked to draw the meanings of some pro-forms such as them, their by referring to a particular reading text (Nuttall, 1996, pp. 86-88). In reading test one, this skill was represented by items number 8 and number 9 . In reading test two, this skill was represented by items number 5 and number 7. From the data analysis, it was found out that $37.5 \%$ or 15 answers of respondents' total answers were incorrect.

Interpreting elliptical expression skill or a skill to recognize what elements which are omitted from a sentence or a passage (Biber, Conrad, and Leech, 2002, p. 230) was represented by items number 28 and 29. The measurement of this skill was found out by looking at the abilities of the respondents to fill in the omitted part of a sentence with a suitable word which the re- 
spondents could guess by searching the context and retrieving the required word to complete the sentence. There were 15 wrong answers $(37.5 \%)$.

The items number 19 and 20 represented structural clues: morphology (word part) skill. The respondents were asked to divide some words into suitable parts: prefix, root, and suffix. The results showed that $35 \%$ of respondents' answers were incorrect.

In using a dictionary, the readers should be able to select, from several meanings offered in the dictionary, the one that is relevant to the given sentence or text in which a particular word occurs (Nuttall, 1996, p. 76). In this study, the respondents had to use this skill in doing items number 21 and 22 . The respondents were asked to choose the suitable dictionary meanings of the same word which occurred in two different sentences. $30 \%$ of respondents' answers were incorrect.

Dealing with interpreting lexical cohesion skill, the respondents had to interpret different words which refer to a similar thing (pp. 91-92). In reading test one, this skill was represented by items number 5 and number 11 . In reading test two, items number 2 and number 11 represented this skill. There were 11 wrong answers $(27.5 \%)$ from the total answers of all respondents.

In this study, recognizing implications and making inferences skill was represented by items number 13 and 14. In answering these test items, the respondents had to infer the message which is conveyed by a reading text (Brown, 1994, p. 295). The results of data analysis showed that $22.5 \%$ or 9 answers were incorrect.

In both reading test one and reading test two, items number 26 and 27 tested the respondents' abilities to "distinguish fact from opinion" (McWhorter, 2002, pp. 418-419). The respondents were asked to decide whether a particular statement which was taken from the reading text was true or false. It was found out that only $17.5 \%$ (or 7 answers) were incorrect.

In this study, the respondents' abilities to improve reading speed which means reading in meaningful chunks (Nuttall, 1996, p. 55) was tested by items number 17 and $18.10 \%$ or 4 answers from the total answers were wrong.

Recognizing presupposition underlying the text means an ability to identify the presuppositions, i.e. knowledge, experience, opinions, attitudes, or emotions which the author of the reading text expect the reader to have, share, or at least understand (pp. 8-9 and 112-113). In this study, the respondents were asked to give respond to items number 15 and 16 which stated the pre- 
suppositions made by the author of the reading text. From the total respondents' answers, there were 4 (10\%) wrong answers.

Scanning skill is defined as "a quick reading, focusing on locating specific information" (Macleod, 2005, p.3). In this study, the respondents were asked to answer questions which tested their ability in finding specific information. In reading test one, items number 3 and 12 represented this skill. In reading test two, this skill was represented by items number 3 and 10 . There were some mistakes ( $7.5 \%$ or 3 numbers) from the respondents' total answers (40 answers). The few numbers of incorrect answers indicated that respondents did not have any difficulty with this skill.

\section{DISCUSSION}

The most difficult reading skill for these students was recognizing text organization $(72.5 \%)$. Perhaps it was because many Indonesian students were not trained to activate recognizing text organization after they read a passage. Usually, they were asked to answer some set of questions after reading a text. Thus they might not get enough exposure towards this skill.

The second most difficult reading skill for these students was paraphrasing (65\%). It could be because they had not fully understood the ideas of the original passage or sentence. It might also because they were not able to restate the ideas of the original passage or sentence in their own words, although, they understood the idea of the original passage. In order to be able to use different words to restate the idea of the original passage, the reader had to have good vocabulary skill. However, it was found that vocabulary skill was the third most difficult reading skill for these respondents (57.5\%).

Inference from context skill was one of important word attack skill which was needed by the respondents to deal with new or difficult vocabularies. The high percentage of the total number of respondents' wrong answers toward inference from context skill's items (57.5\%) was in line with Parry's study (1991, as quoted in Grabe and Stoller, 2002, p. 131) which stated that none of her respondents were very successful in guessing word meanings from context. They had already tried to guess word meanings from context, but their answers often turned out to be wrong.

In this study, it was found out that there were only three wrong answers (7.5\%) from the total respondents' answers toward scanning skill's items. Therefore, it could be assumed that students did not have much difficulty with 
this skill. It might be because they had already been trained to use this skill in all reading classes. As a result, they could use this skill effectively.

The other reading skills which had low difficulty level were improving reading speed $(10 \%)$ and recognizing presupposition underlying the text $(10 \%)$. This finding indicated that the respondents were good readers because they were able to read fast and in meaningful chunks. As fast readers would have a better understanding, it was not surprising to find that the respondents did not have much difficulty in recognizing the author's presupposition of the reading texts included in this study.

\section{CONCLUSION AND SUGGESTION}

Though this present research was a small scale one, the findings discussed in this study showed that each reading skill had different level of difficulty for the respondents. Further research could be conducted on a larger scale which larger number of reading tests covering larger number of items each reading skill could be administered. Larger number of respondents could also be used to produce wider results which could be used to make generalization.

\section{REFERENCES}

Biber, D., Conrad, S. \& Leech, G. 2002. Longman Student Grammar of Spoken and Written English. Harlow: Pearson Education.

Brown, H. D. 1994. Teaching by Principles: an Interactive Approach to Language Pedagogy. New Jersey: Prentice Hall.

Bryndal, M. 2007. The Importance of Predicting and Iinteracting with Texts in Developing Learners' Reading Skills. Retrieved 19 February 2007 from http://www.developingteachers.com/articles tchtraining/reading1_malgool zata.htm

Grabe, W., \& Stoller, F.L. 2002. Teaching and Researching Reading. Harlow: Pearson Education.

Hughes, A. 1989. Testing for Language Teachers. Cambridge: Cambridge University Press 
Macleod, M. 2005. Types of Reading. Retrieved 13 March 2007 from 'http://fis.ucalgary.ca/Brian/611/readingtype.htmi \#overview

Mahfoodh, O.H. 2007. Reading for EFL College Students. Retrieved 17 Febru-

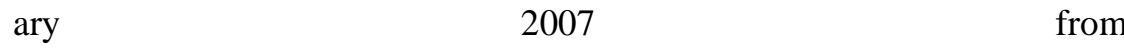
hhttp:///www.yementimes.com/article.sthml?i=1023 $\$ \mathrm{p}=$ education $\& \mathrm{a}=3$

Maker, J., \& Lenier, M. 1986. College Reading (second edition). California: Wadsworth.

McDonough, J., \& Shaw, C. 2003. Materials and Methods in ELT : A Teacher's Guide (second edition). Oxford: Blackwell.

McWhorter, K.T. 2002. Efficient and Flexible Reading (sixth edition). New York: R.R. Donnelley and Sons.

Nation, I. S. P. 1979. The Curse of the Comprehension Question. In Khoo, R. (ed). Guidelines for Teaching Reading Skills (pp. 85-103). Singapore: SEAMEO Regional Language Centre.

Nuttall, C. 1996. Teaching Reading Skills in a Foreign Language (new edition). Oxford: The Bath Press.

Parry, K. 1991. Building a Vocabulary through Academic Reading. TESOL Quarterly 16 (2). 185-194.

Suparman, U. 2005. A Comparative Study of Characteristics Between High and Low Students' Reading Proficiency. English Edu 5(2), 140-158.

Talok, D. 1992. Reading Comprehension Exercises for Intermediate Readers. Yogyakarta: Kanisius.

Wassman, R., \& Rinsky, L.A. 2000. Effective Reading in a Changing World (third edition). New Jersey: Prentice Hall.

Weir, C. 1993. Understanding and Developing Language Tests. New Jersey: Prentice Hall. 